

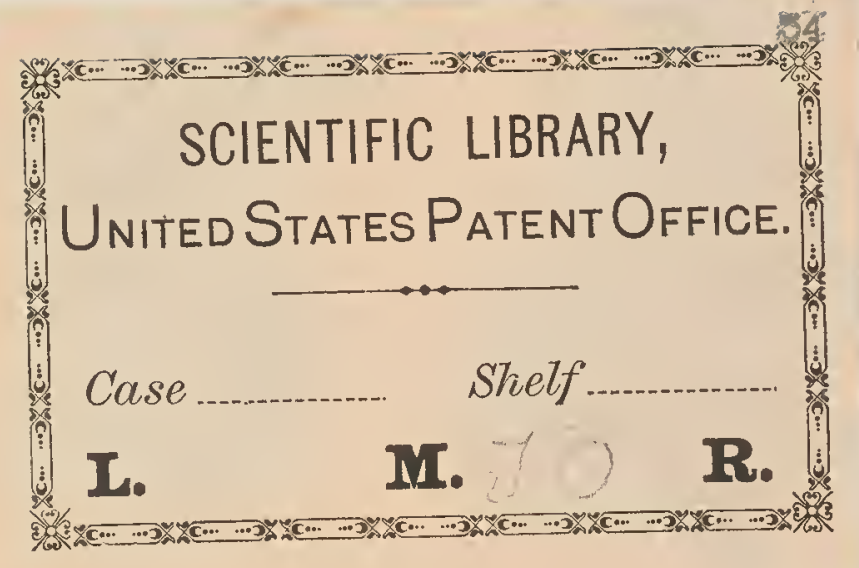






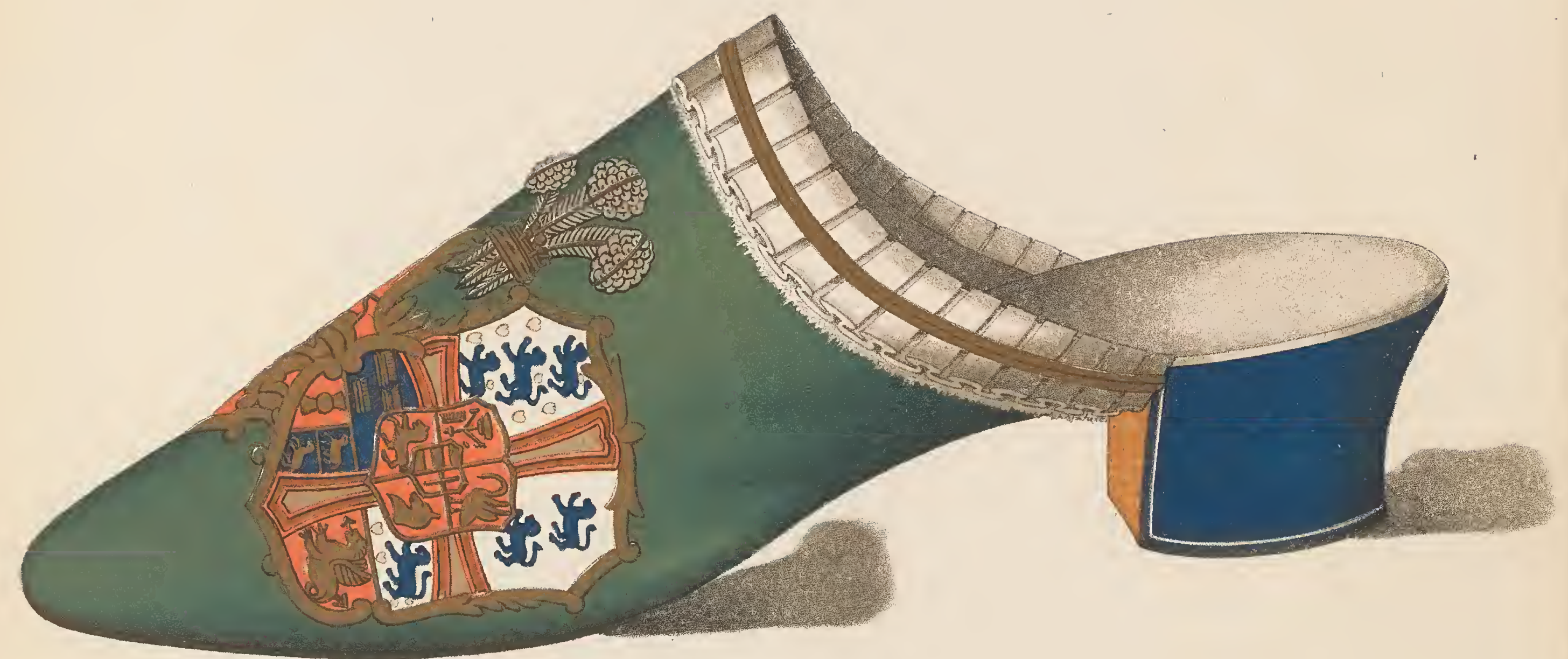




\title{
Ladies' Dress Shoes of the
}

\section{Nineteenth Century}

\author{
With Sixty-three Illustrations
}

BY

\section{T. WATSON GREIG OF GLENCARSE}

Autbor of

“Ladies' Old Fashioned Shoes"

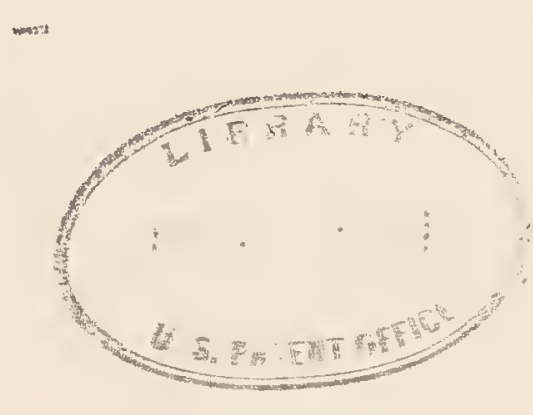

EDINBURGH : DAVID D OUGLAS 



\section{Preface.}

THE sixty-three ladies' shoes now illustrated have all belonged to and been worn by ladies of the i 9 th century. They have been most carefully selected to illustrate the variety and change of fashion during that period. The shoes can be copied in any material by any shoemaker. I beg to return thanks to all those who have been so kind as to give me their assistance in collecting them.

Glencarse, 28th May 1900. 



\section{Frontispiece.}

This specimen of Mule or Bedroom Slipper is in green velvet, on which the coat of arms is embroidered in rich silk and metallic threads. The front is finished off with a white silk ruche, held in place with a row of narrow gold braid, and the lower outline softened with an edging of fine blonde lace. The heel is covered with royal blue satin, and the lining is white. The maker is Abrahams, Westbourne Grove, W. 



\section{Plate I.}

WE have in this illustration three fine specimens of the modern shoemaker's craft. The general shape of the shoes is much the same, but what may be called the decoration is varied. The satisfactory use of the "Magpie" colours is striking, and argues the good taste of the worker, and the designs, though simple, give scope to great excellence in workmanship.

The cordonnier artist has apparently considered his lines as carefully as the best of yacht builders. The material employed in the first two instances is kid, and in the other black and white velvet. 

Plate I.
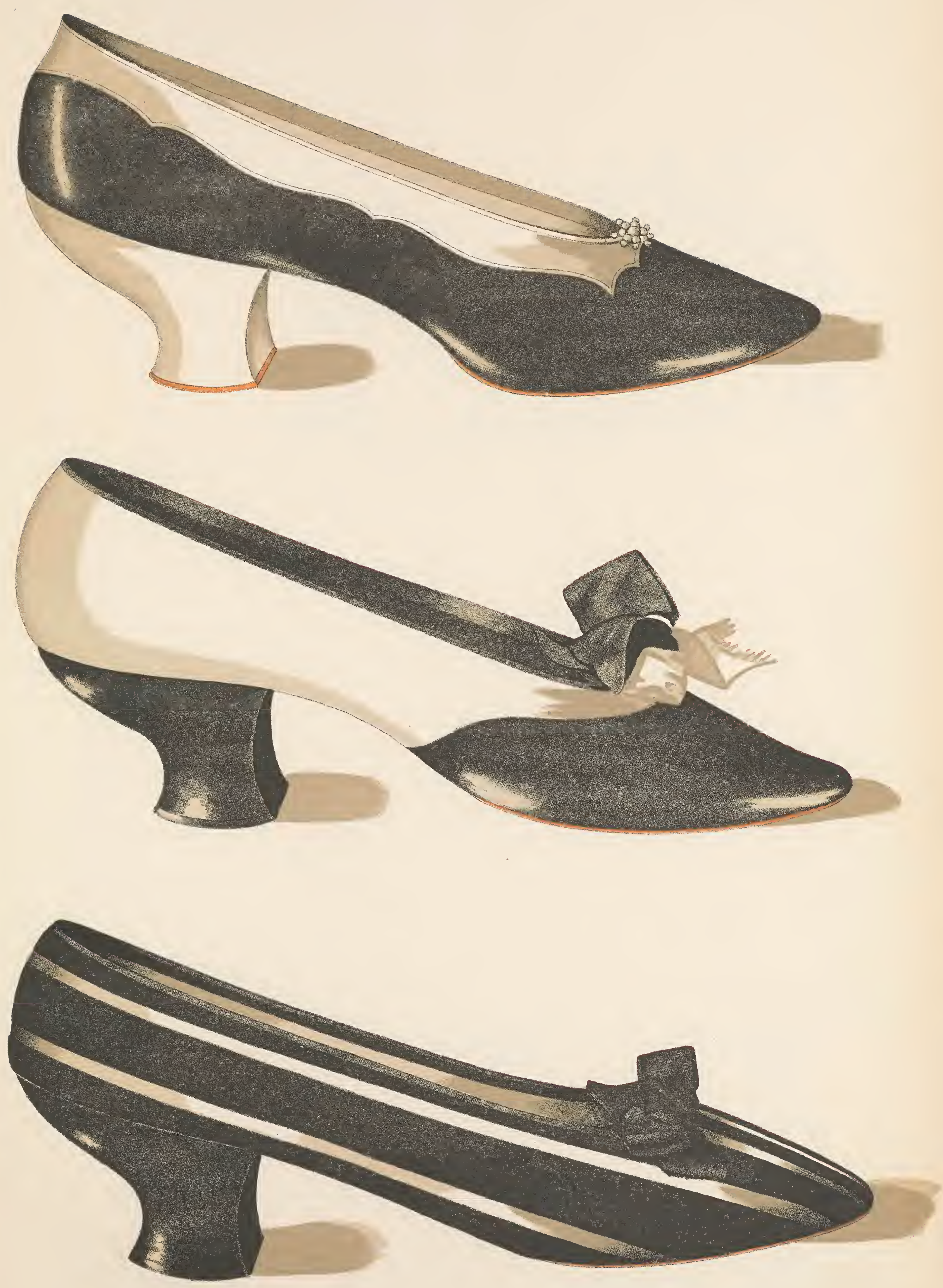



\section{Plate II.}

Illustrates three black satin shoes. The first, without heel and very square toe, was, no doubt, comfortable, but decidedly unshapely foot-gear. The sole is thin, and there is no attempt at ornamentation, even to hide the elastic ankle strap. As this shoe dates back a considerable number of years, it serves to show the many modern improvements of its two companions.

No. 2 has a general appearance, which at once demands admiration. The heel is medium, the toe pointed, and the ornament is a trefoil in old paste. This shoe belonged to Mrs Macandrew of Dalcross Castle, N.B., who may be congratulated on its size, or, rather, want of size, and on the good taste which chooses a plainness of style embodying the essence of smartness. The Jubilee Shoe has Louis heel, and is embroidered with the Royal Crown and initials, V.R., with motto, "God save the Queen." This shoe was designed in honour of Her Majesty's first Jubilee, 1887. In I 897 a similar shoe appeared with the Crown, date, and wording, "Sixty Years Celebration." 



\section{Plate il.}
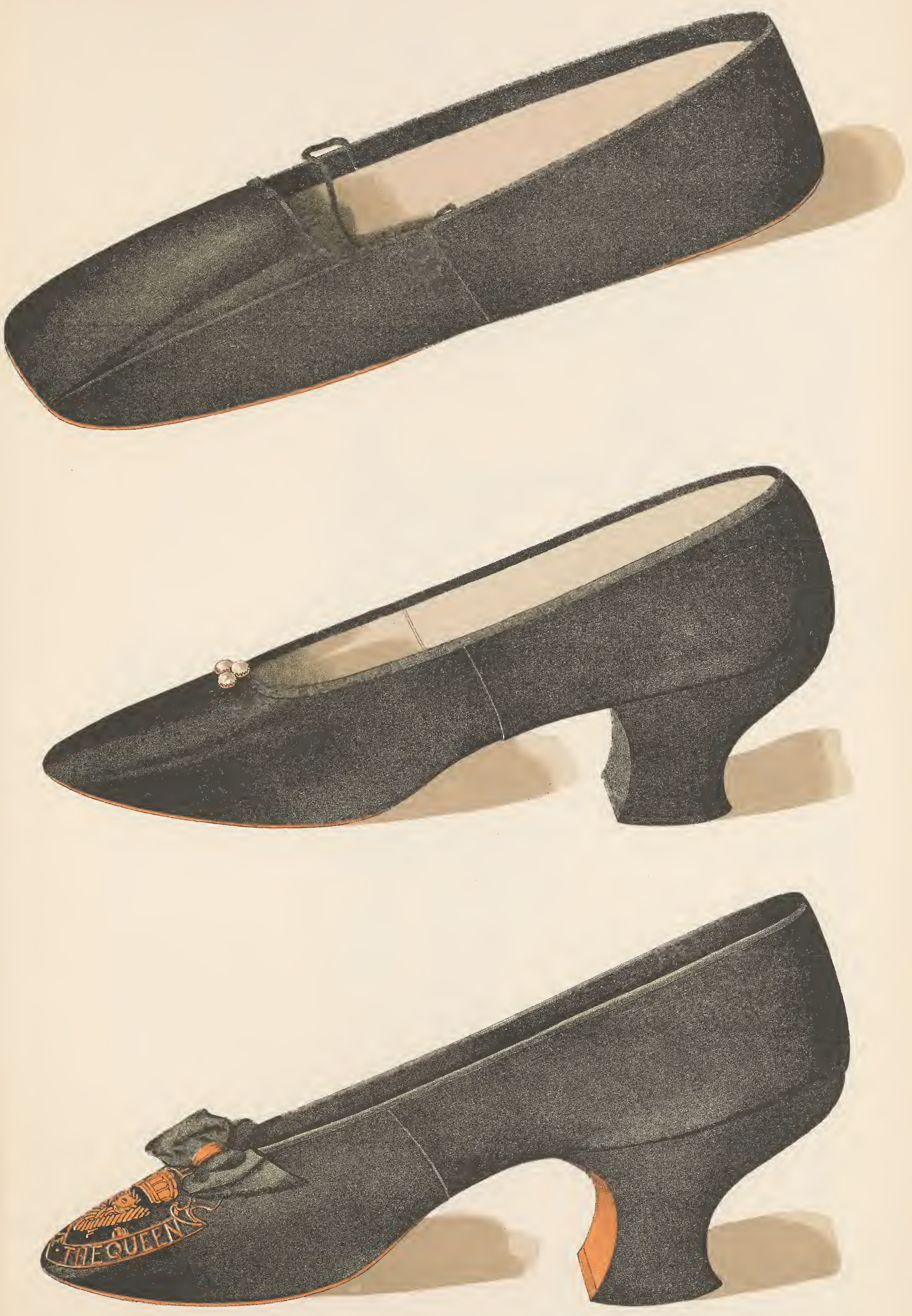



\section{Plate III.}

Bronze stage shoe worn by the well-known actress Miss Ada Cavendish. Louis heel, somewhat square toe, embroidered finely with steel, and large brown satin-pleated bow with steel buckle.

Bronze shoe No. 2 is one of the smallest in the collection, and belonged to Miss Marsh. It has a pointed toe, Louis heel, and plain little bow of brown satin ribbon.

The third shoe, also in bronze, has very pointed toe, with pearl and gold embroidery, which also adorns the small bow, leaf-like in form. The side seam is stitched with silk galloon, similar to what binds the outside edge. The heel is Louis in style. 

Plate iII
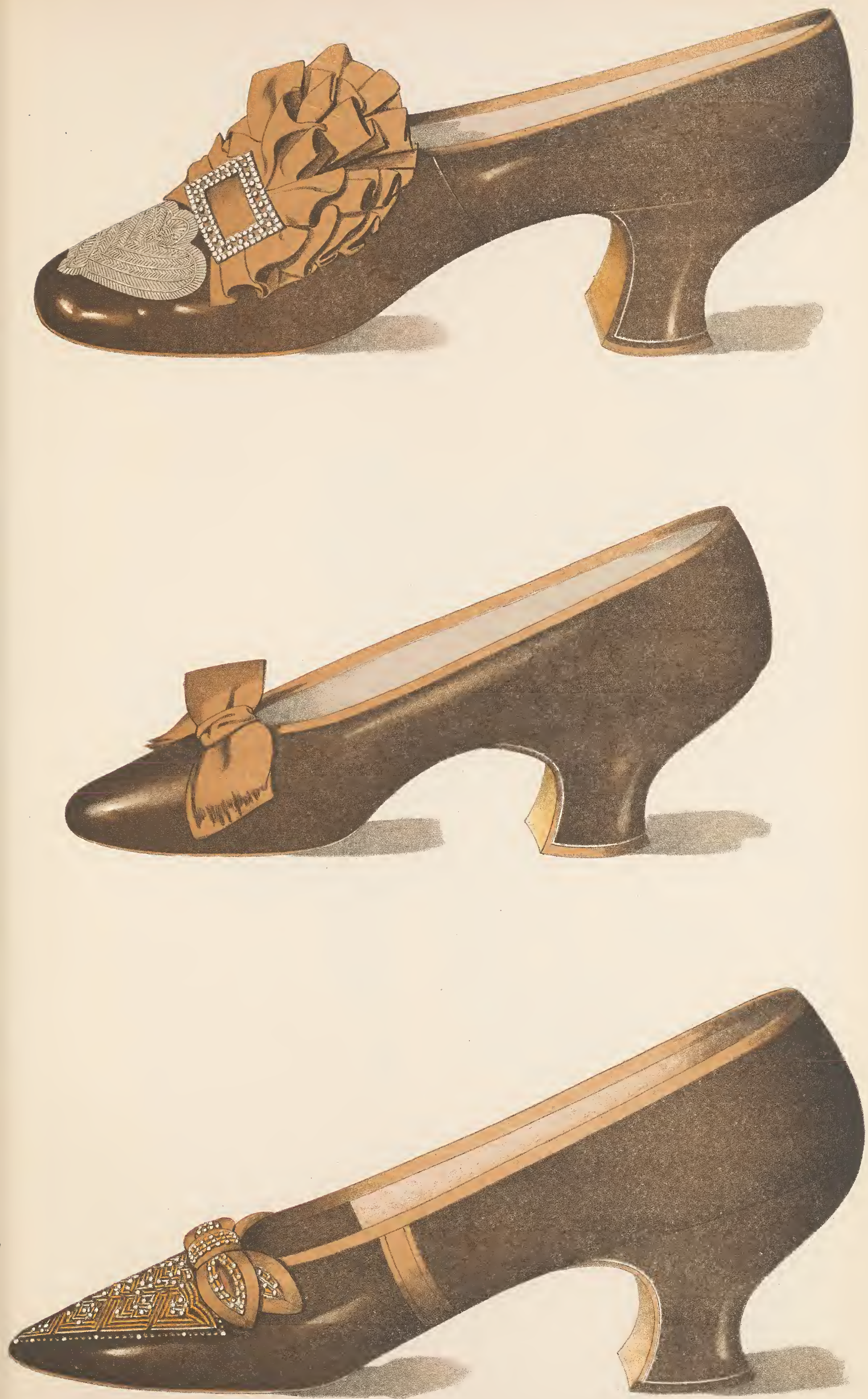



\section{Plate IV.}

This elegant shoe resembles a little its immediate predecessor in Plate III. in the heel, bow with four small leaves, and the ribbon-covered side seam, and, indeed, reflects the style of the same maker, with the difference shown in the embroidery, which completely covers the pointed toe, and is of rich gold thread. Gold beads further enhance the bow. The kid is bronze.

Bronze also No. 2, with interlaced yellow ribbon in diamond pattern. This design of stitched ribbon is a good idea to make a self-coloured shoe correspond more closely with costumes in mixed hues. The round ornament is gilt, and the heel an ordinary one.

The next shoe is in black glacé kid, and belonged to the late Duchesse d'Aumâle. The toe is square, Louis heel, and the "ruched" rosette is of black silk, edged with puce. 

Plate iv.

6.

-
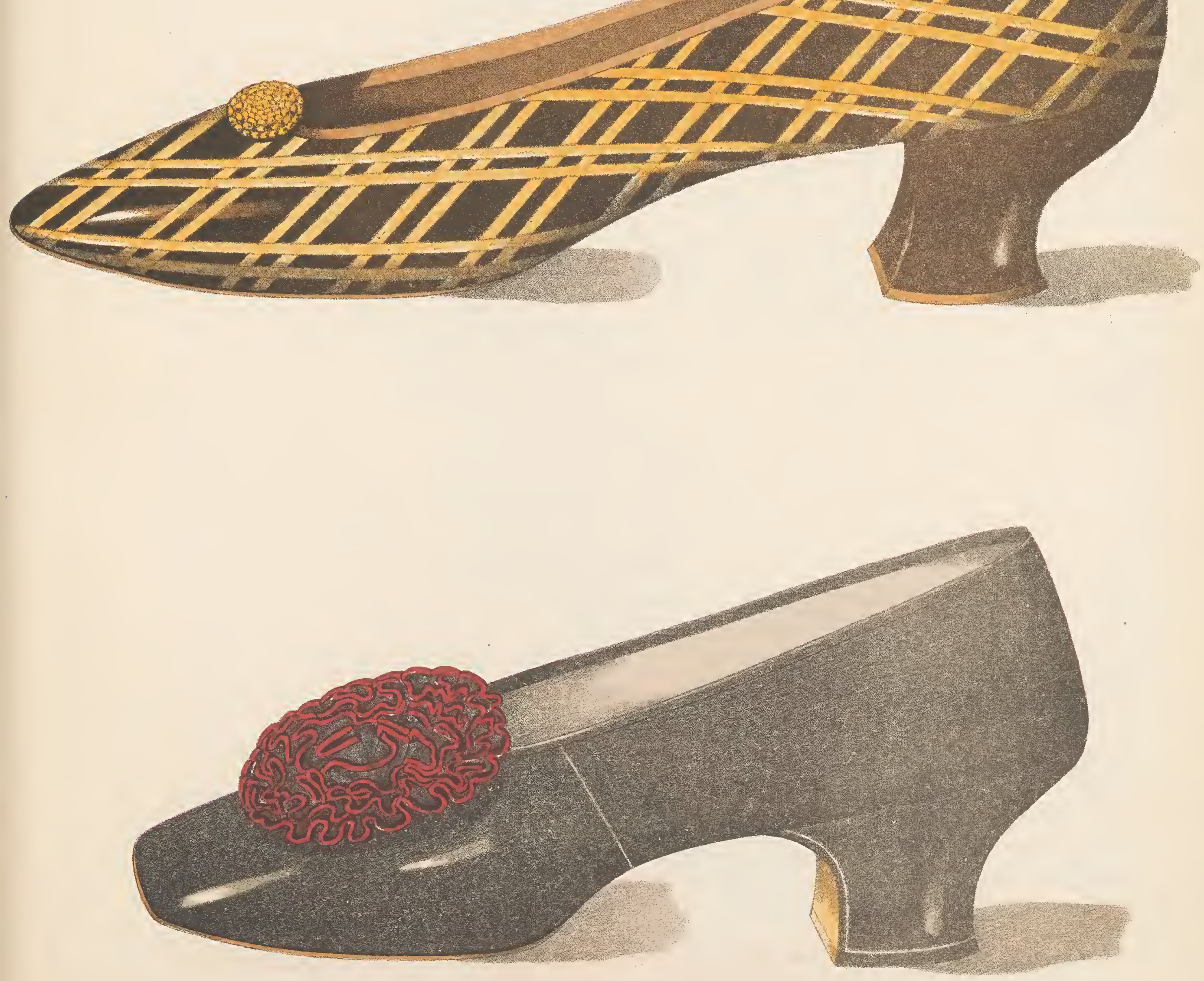



\section{Plate V.}

No. I.-Pink kid shoe, with round toe, ordinary heel, and lined white kid. The knot-bow is in pink silk ribbon, with picot edge.

The late Marchioness of Ely owned the centre shoe. It is in rich pink satin, ornamented with round real lace rosette, and has Louis heel and square toe.

Plain pink satin shoe--the 3rd--very neat in shape, with ordinary heel, and trimmed small bow of same pink satin as the shoe.

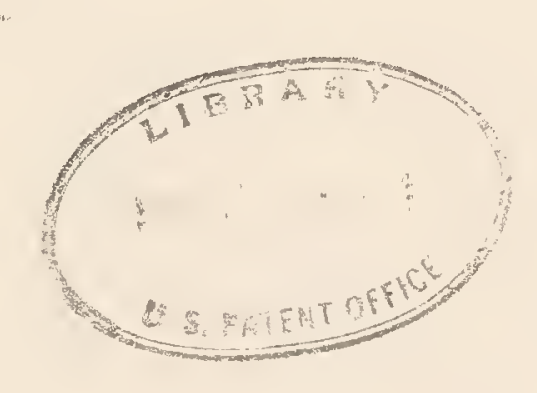




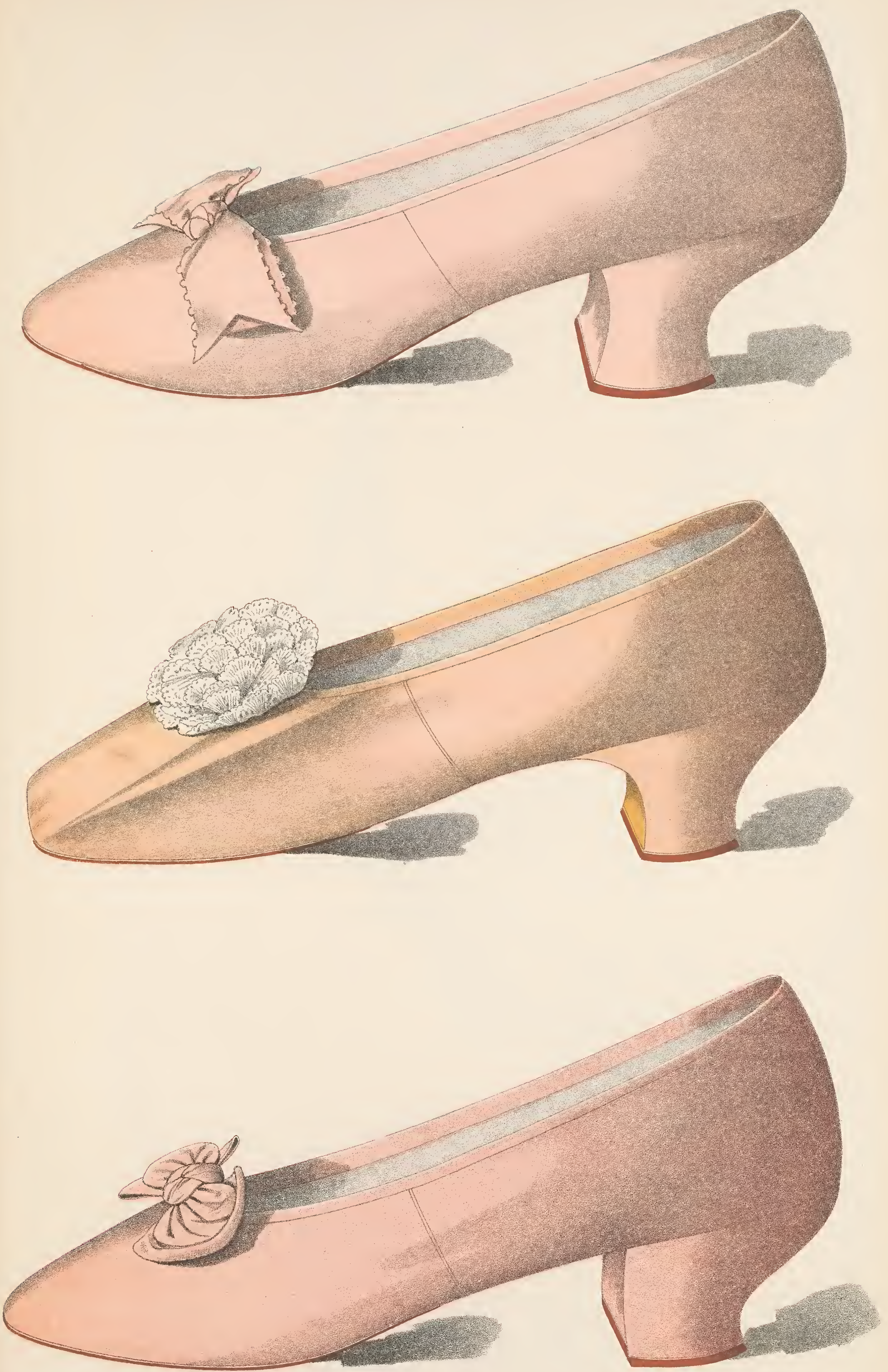



\section{Plate VI.}

Here appears another of Miss Ada Cavendish's shoes, worn on the stage. It is of bright yellow satin, trimmed silver braid, which mingles also with the satin in the round rosette, with mother-of-pearl centre. The toe is very square, this actress being slow to adopt the pointed toe now so much in vogue.

No. 2, yellow satin shoe, has silk embroidery, studded with orangetinted cabochons, and the bow of crimson silk gives an uncommon finish. Pointed toe and ordinary heel.

The third is of plain straw-coloured satin, made uncompromisingly to match costume without further decoration than the bow, formed of the same material. 




\section{Plate VII.}

Single strap shoe, in French grey satin, the front in a certain manner unattached from back, and distinguished from the same by elaborate floral embroidery in silk and iridescent beads, which figures also on the strap. A single paste stone forms central finish to this shoe-uncommon in shape and design.

The second shoe, deeper in hue, is said to have belonged to Mrs Grahame; and its central tongue, with two overlapping flaps, which call for a necessary buckle of paste or silver, would place its date in the early part of the century.

The silver embroidery in thread, tiny sequins, beads, and lace is in admirable taste; and the whole workmanship of the shoe, which is in excellent preservation, is of the best order.

The last shoe is of plain blue satin, with handsome decoration of gold tinsel embroidery, studded with oval turquoises, and supplemented with the brightness of crystal beads, being similar to the trimming of the dress. 


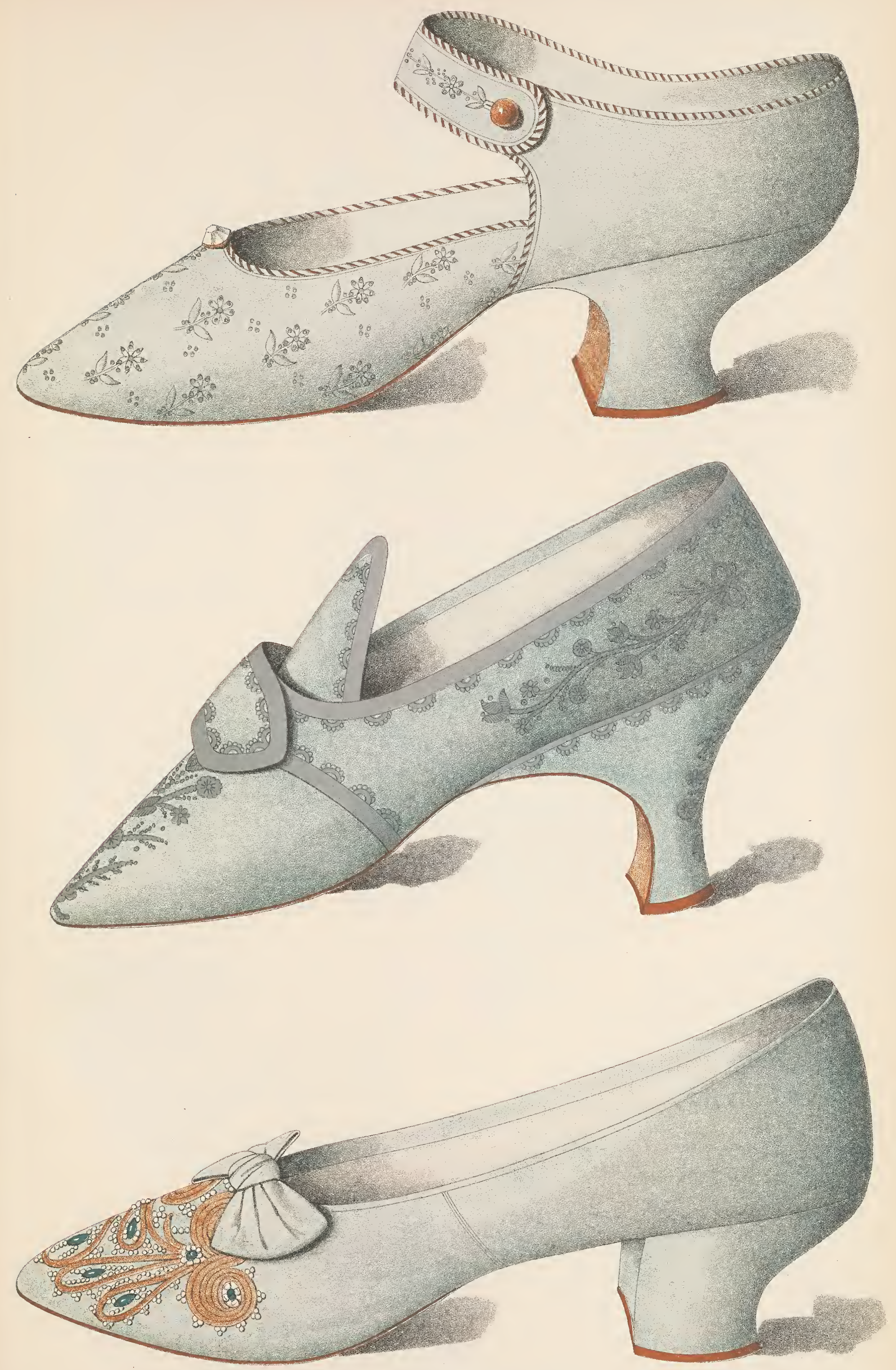



\section{Plate VIII.}

THIS shoe-Figure I-bears the print of its French origin in its essential smartness, combined with neatness and uniformity of colouring-namely, a deep, rich purple satin, the bow being of velvet in similar shade. It was worn by a member of the Rothschild family at the time of the Queen's first Jubilee, and the maker, Meier of Paris, not only has a great monopoly in the clothing and adorning of fashionable feet, but is also much in request in successfully fulfilling stage taste and requirements in shoes.

The second shoe on the page is of very small size, and is of English make, though owned and worn by the French Duchesse de Beauprémont. It is of bright blue silk, with large rosette and peculiarly shaped heel, being much elongated underneath towards the side seam.

The next, pale blue silk shoe, is made simply to match a gown, and probably out of the same fabric. 


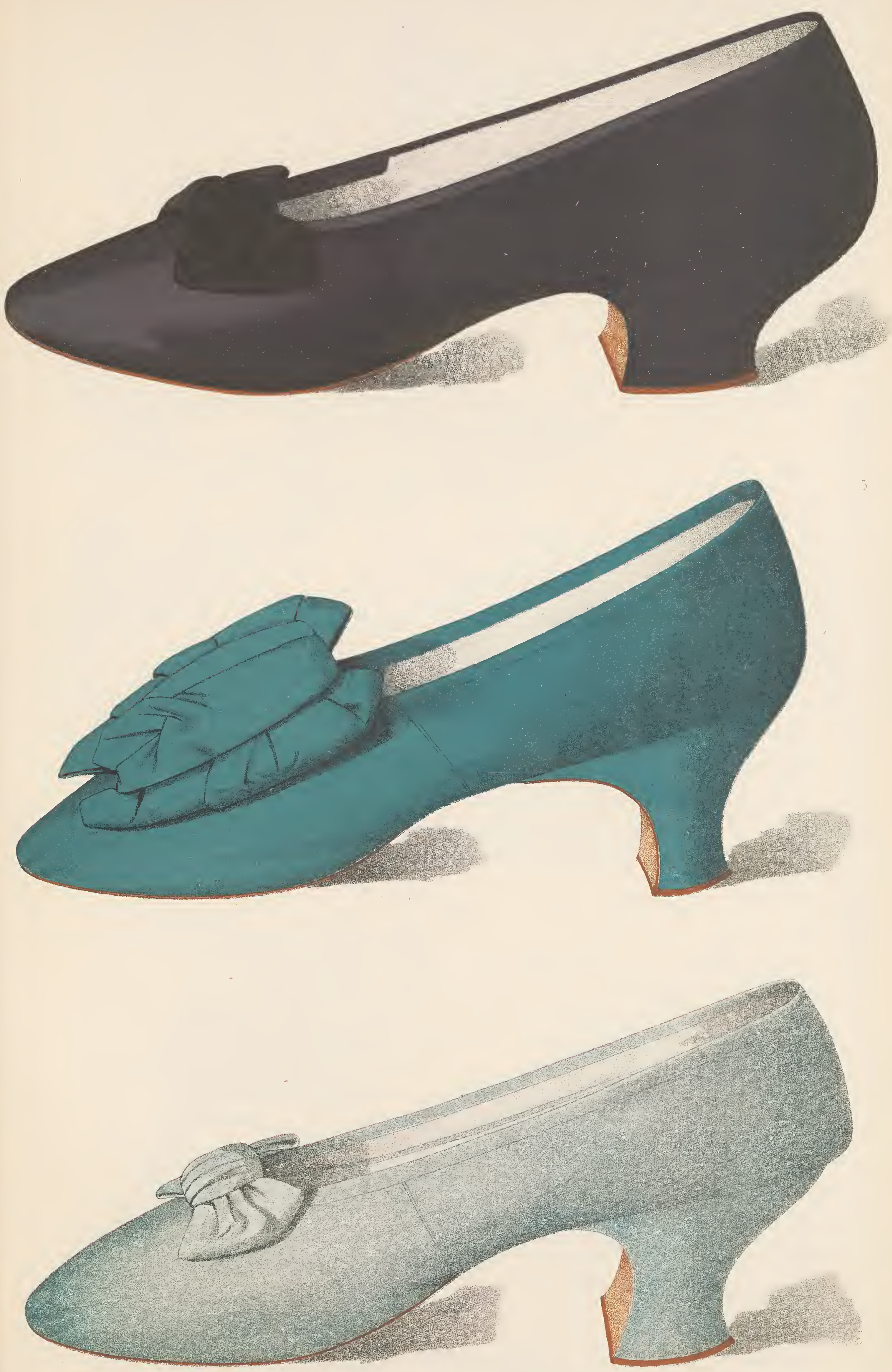



\section{Plate IX.}

The first shoe of this plate would be remarkable for neatness, though it might be thought somewhat spoilt by a squareness of toe, but it will be noticed the idea of squareness appears carried out otherwise in the cut of the shoe. The space between the principal strap and the three small ones crossing the foot makes an uncommon variety. The little bows of twilled silk (of which the shoe also is constructed) give a chic, if somewhat formal finish, to each band. The heel is a Louis shape.

Figure 2 belonged to an Edinburgh belle of the season of 1872 , and is of tiny dimensions, though the old fashion of ornamenting with a large bow deprived the wearers of these small sizes of some of the credit.

The third and most elegant shoe possesses one of the highest Louis heels worn off the stage, and belonged to an American lady who, like several others, came to this country and acquired for herself the right to the motto first adopted by Alexander the Great-namely, "Veni, Vidi, Vici." 


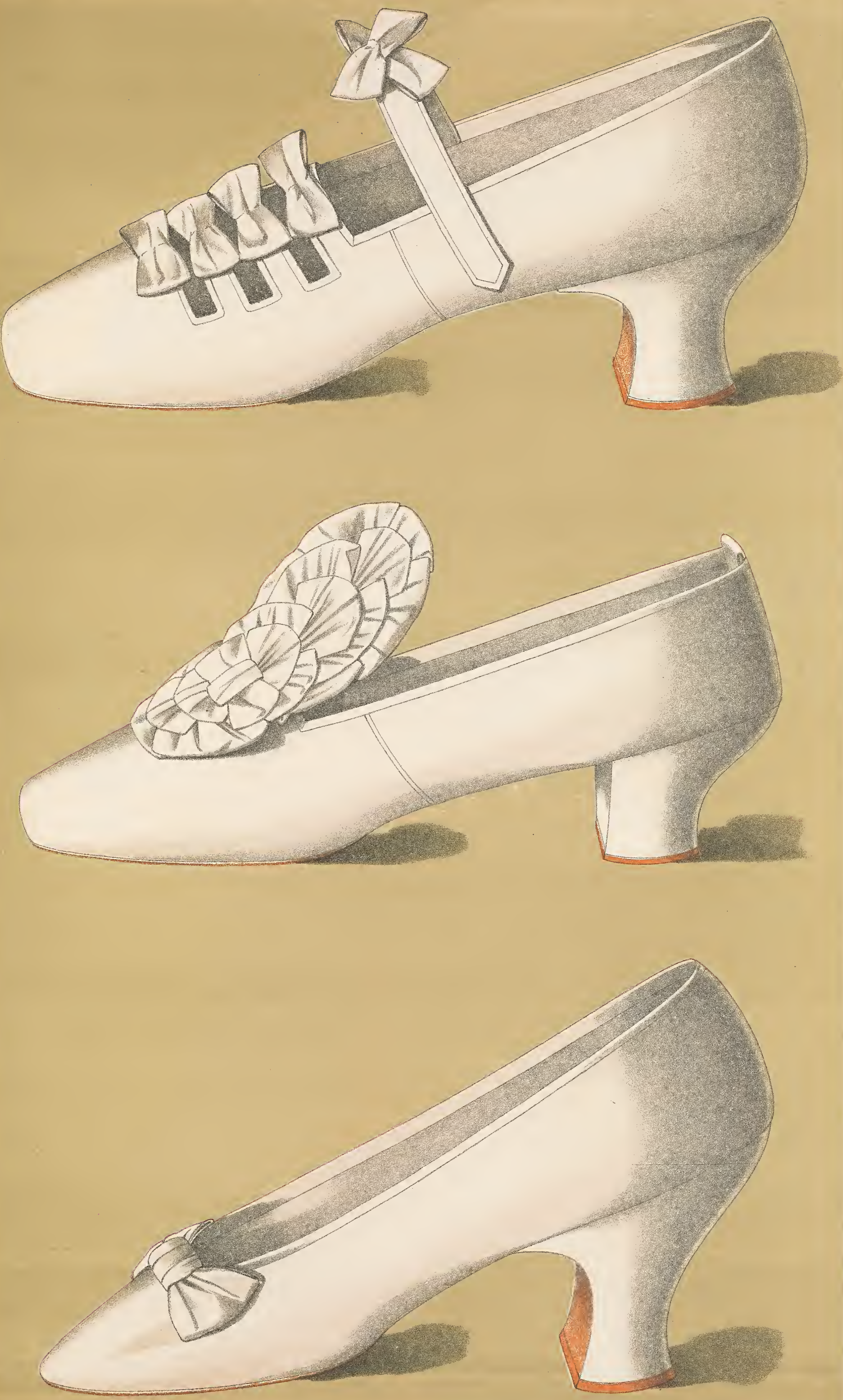



\section{Plate X.}

This shoe of white silk has the novel decoration of small netted buttons. These buttons rest on simulated straps, the silk being merely cut away to show spaces of the blue lining between. The shoe has altogether a perfection of style which its distinguished owner, an autocrat in dress, always demands.

No. 2 is of very small size in white satin, richly embroidered in crystal beads and thick silk twist. The open-work meshes, like spider webs, could reveal a pretty shade of stocking.

The latter idea, however, is carried out to perfection by $\mathrm{No}_{0} 3$, a shoe which is composed entirely of strong cream silk guipure. It is eminently fitted for evening - especially dancing - wear, both as to texture and coolness. The pattern of the lace in this example adapts itself to the neatest and smallest of shapes. The back is kept in shape with satin-covered stiffening. 


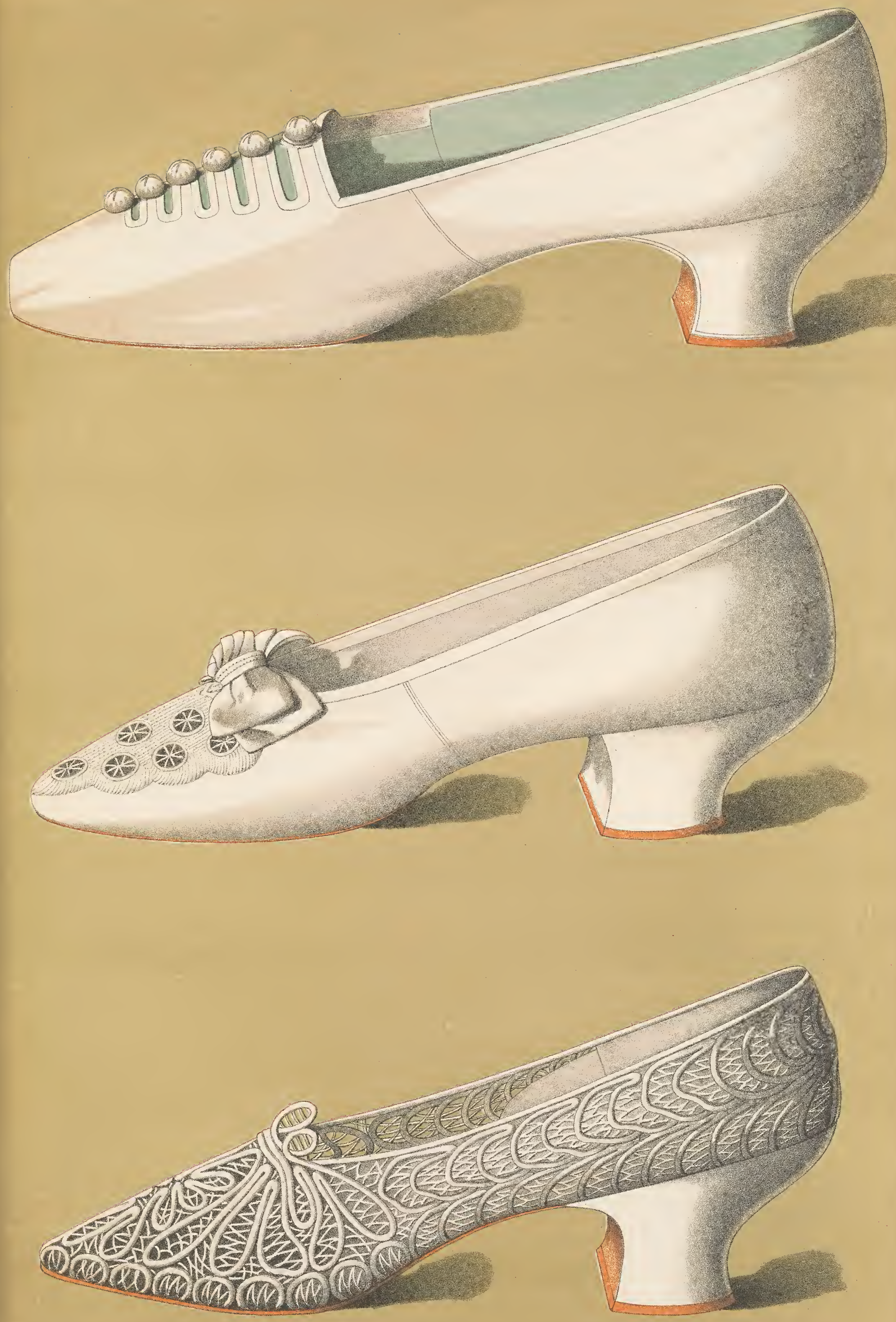



\section{Plate XI.}

THIS shoe of Cromwellian shape hails from the stage, and boasts the highest heel in the collection. It is thickly embroidered in small crystal beads studded with cabochons, the latter also in clear crystal, which is a decoration difficult to beat. The wide tonge is kept in place by a strap, which would require a diamond or silver buckle to fasten it at the side, not visible in the illustration. The lining is of pale blue satin.

No. 2 is owned by a society belle, whose beauty may be said to extend from "top to toe," as the toe, or rather toes, encased in this foot-gear must be of the smallest and daintiest description, and demanding a share of the admiration granted to their lovely owner's figure and face.

The next shoe is a wedding shoe, looking strange to us in its old-world form, but the very mould of fashion in its day, which dates nearly forty years ago. 



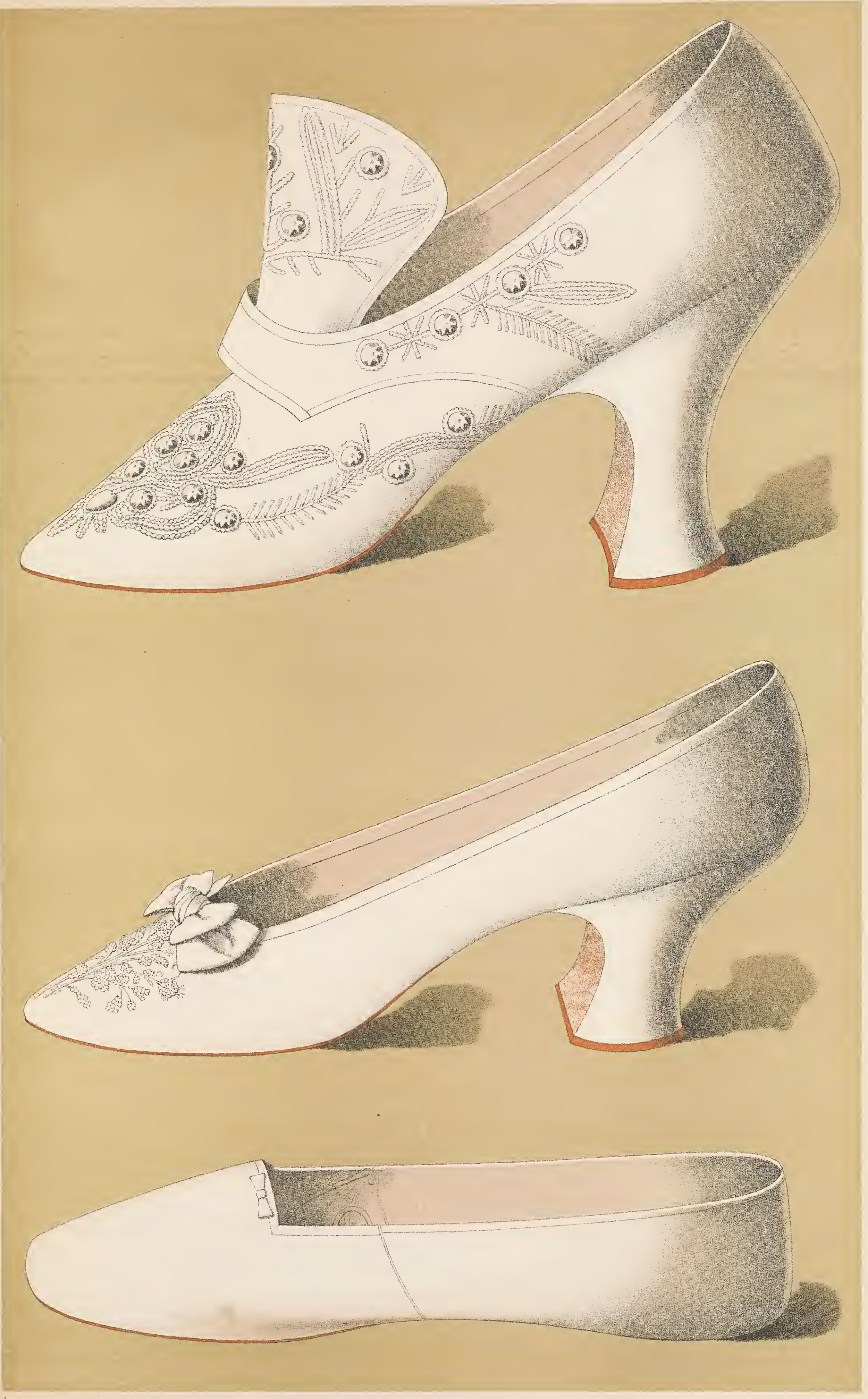





\section{Plate XII.}

A Handsome shoe this of rich silver brocade, with bow of same, pointed toe, and substantial Louis heel. The incurved seam at back gives a firmer hold to heel and ankle.

Miss Edna May owned the centre shoe, and it was worn by her as the "Belle of New York." The embroidery in white silk and silver beads is faultless in design. The heel is an extremity of height, and is much the safer for the single ankle-strap, with its neat bow and ornament.

No. 3, of plain silver kid, has elongated toe, beaded by small silver ornament. It is a suitable shoe for fancy dress, but has this drawbacktogether with its two companions, also much besilvered-a liability to tarnish. 



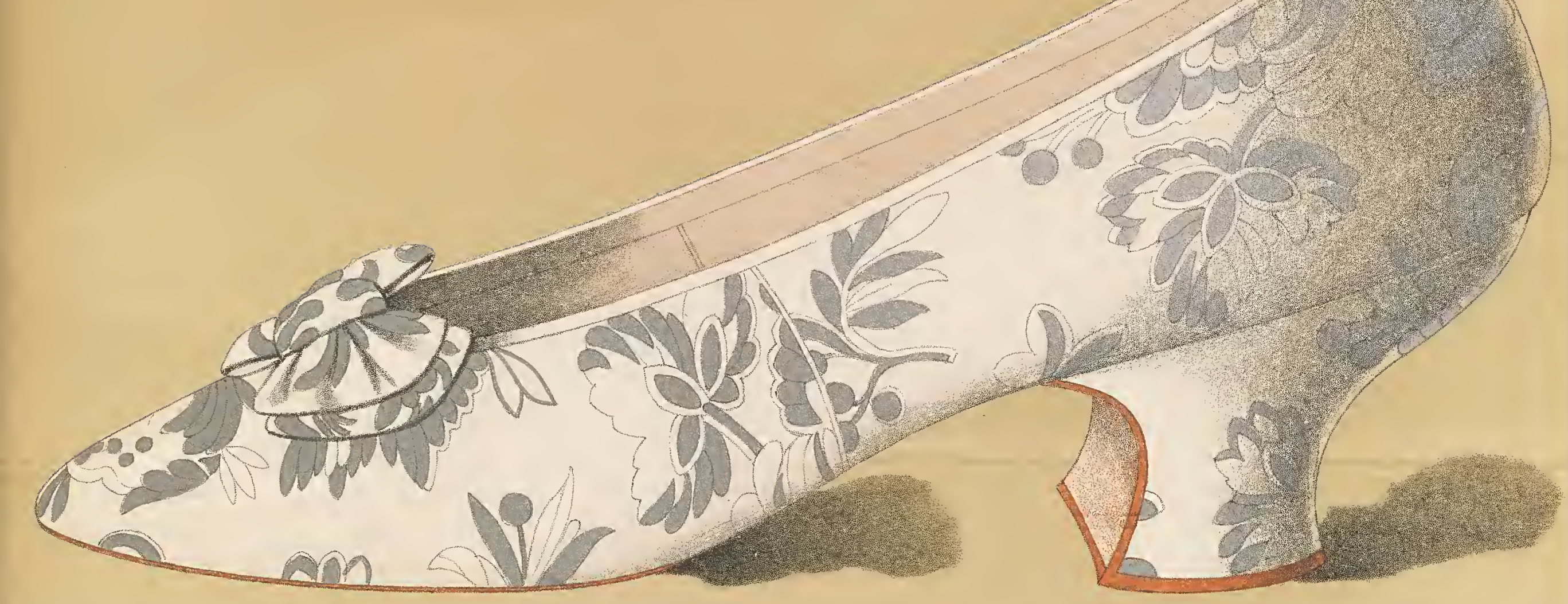





\section{Plate XIII.}

THIS well-shaped boot stands out unique amongst the bevy of surrounding shoes, but its texture, shade, and workmanship are none the less delicate. Its owner and wearer was of exalted position, and her foreign birth, perhaps, inclined her to a departure from the usual style for evening wear.

No. 2 shoe is of a shape frequently made in two shades, but looks no less well for its sameness of colouring in the present instance, with which the neat trio of steel daisies admirably harmonise, adapting it at once to modified mourning if desired.

Last on this page is a bridesmaid's shoe, and it could well be taken as a pattern of style for anyone called upon to enact that part. The bow of silk ribbon harmonises with the heliotrope coloured satin, of which this shoe and its two predecessors are made. 


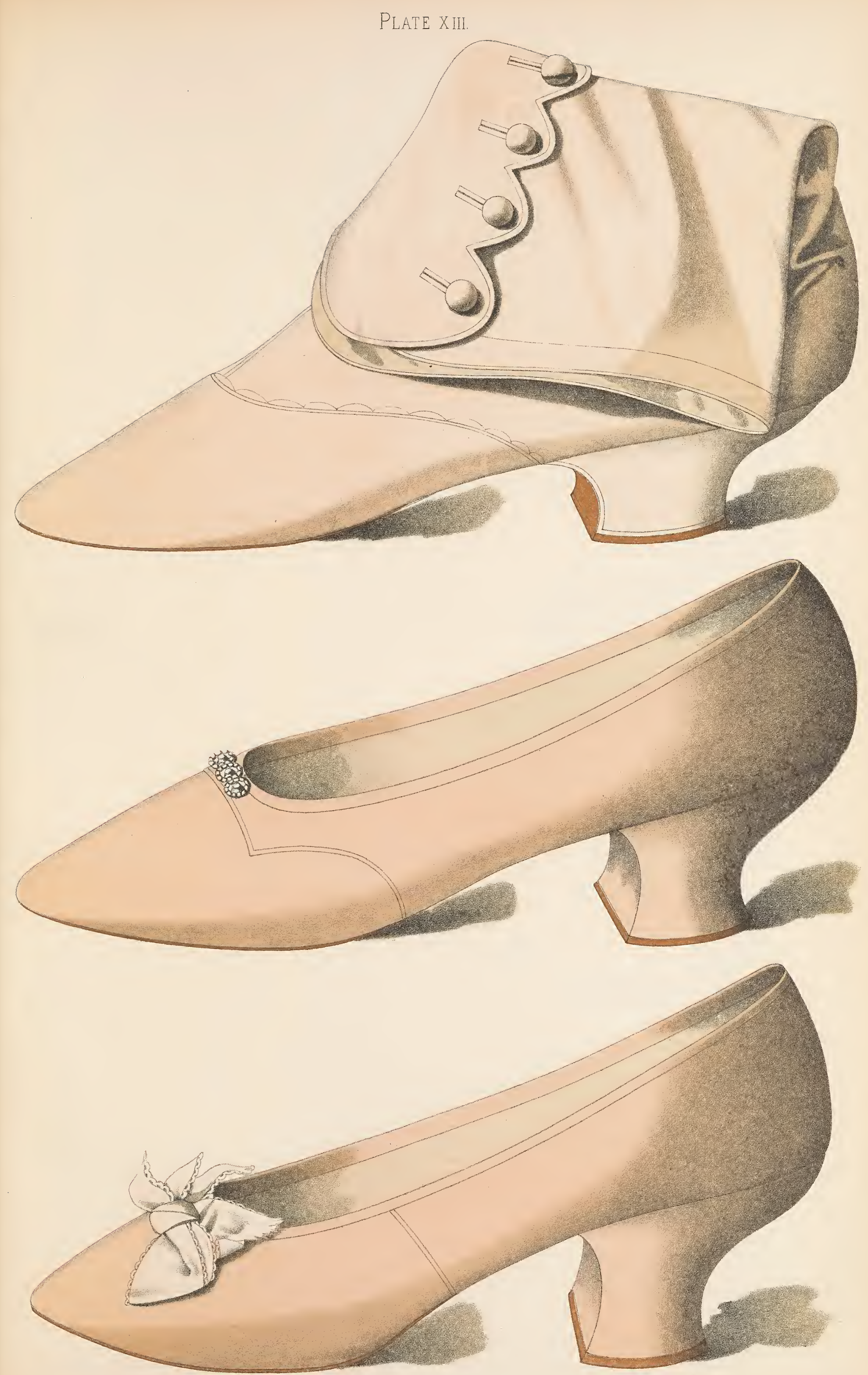



\section{Plate XIV.}

FIRST appears in this shoe a further idea of contrivances for firm wear. This is in the form of a useful elastic strap, covered with heliotrope satin bow to match shoe. It is a more clumsy appliance than the indrawn heel at the top, before described in Plate XII.

The second shoe, also in heliotrope shade, but of silk, belonged to the Comtesse de Paris, and is decorated with real lace. It has a square toe and low heel.

No. 3 is distinguished for its embroidery, the species of flower and the blending of its colours harmonising so well with the lilac colour of satin. 

Platexiv.
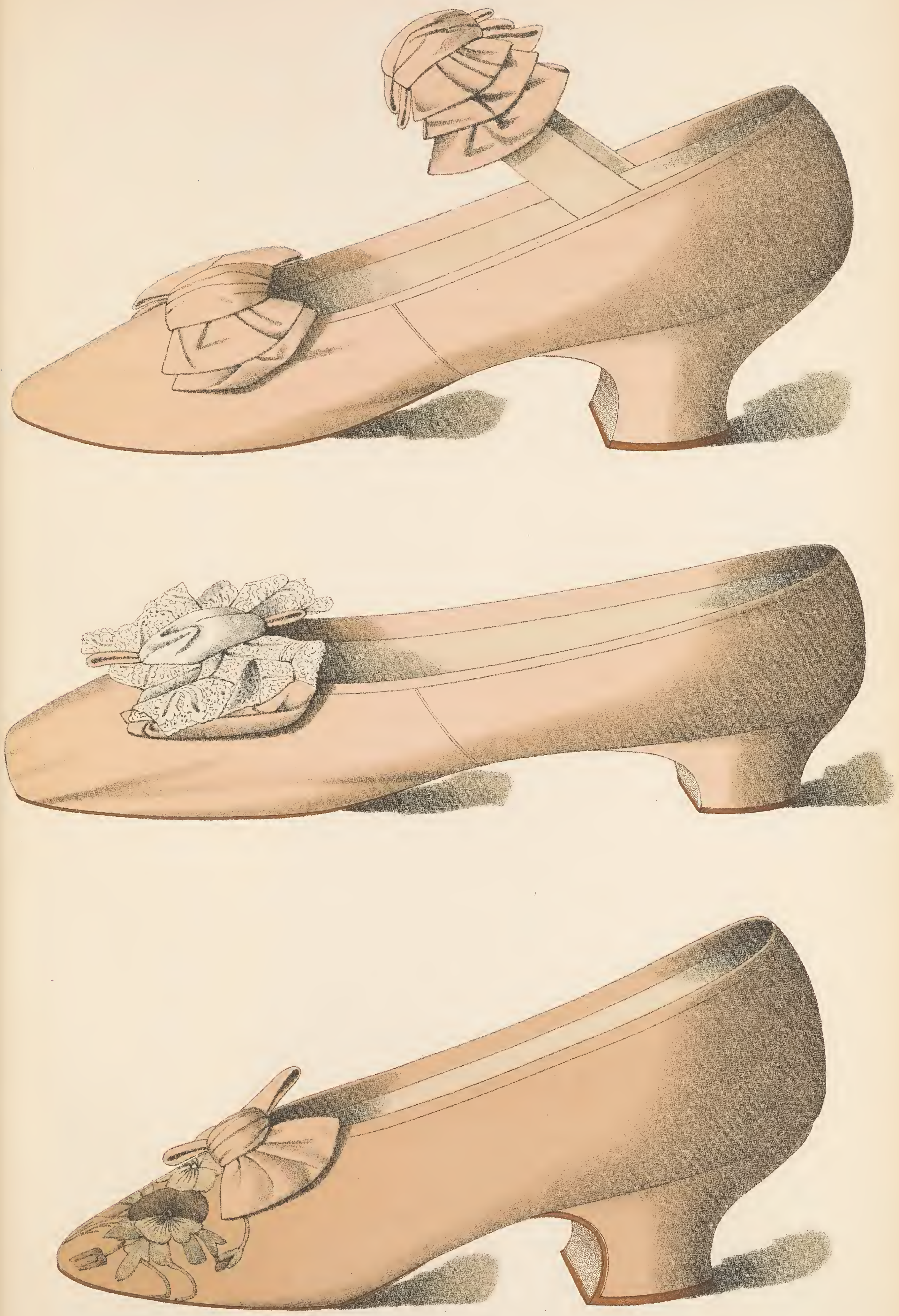



\section{Plate XV.}

FIRST, a shoe which can be certified as Imperial, and bears the French print of good taste in elaboration. The little border of lace all round the edge and also round the bow gives daintiness and lightness, whereas the gold embroidery gives massive richness at the same time. The additional knot of gold lace and tassels is peculiarly handsome and effective, and the rich embroidery and bead work extends even to the heel_an Imperial heel evidently demanding special adornment.

Algiers contributes this specimen of slipper, Eastern in design and shape, and in its lavish covering of patterned gold.

No. 3 is another case of the evening "Oxford" shoe. It is beautifully shaped and free from clumsiness, and the embroidery in lightness and effectiveness of design scores a success. The Duchess who chose and wore it might well be imitated in such a fashion. 


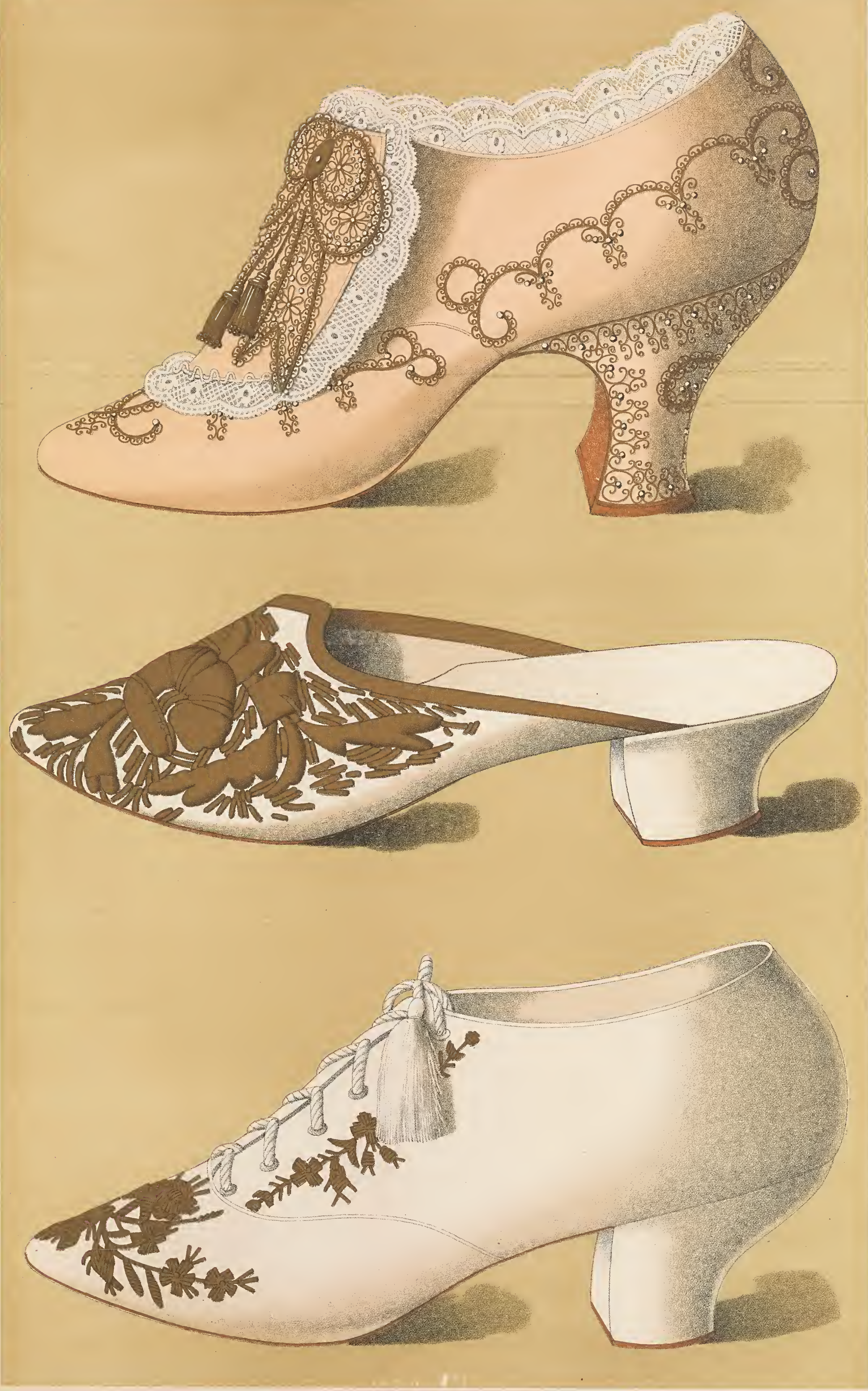



\section{Plate XVI.}

The first shoe on this plate belonged to and was worn by Miss Christine Nilsson in "Lohengrin." It is of cloth of gold, and testifies that the great singer does not neglect, in her superior charm of voice, the additional charm of dress. The gilt buttons are appropriate, and the crystal studs, glistening like dewdrops across the instep, are original in arrangement. The toe is very elongated. Otherwise the shoe is of the ordinary approved shape.

No. 2 is gilded kid, superior to the cloth of woven gold thread from its untarnishable quality. The round gilt button makes a neat finish. The heel is rather low for smart effect.

The third shoe of cloth of gold boasts a Duchess for its quondam owner, who, in turn, can boast that her foot could grace its tiny dimensions. The sole ornament of loops of braid is uncommon, in the fact that it is composed of bullion and not tinsel. The shoe has a Louis heel and white kid lining. 


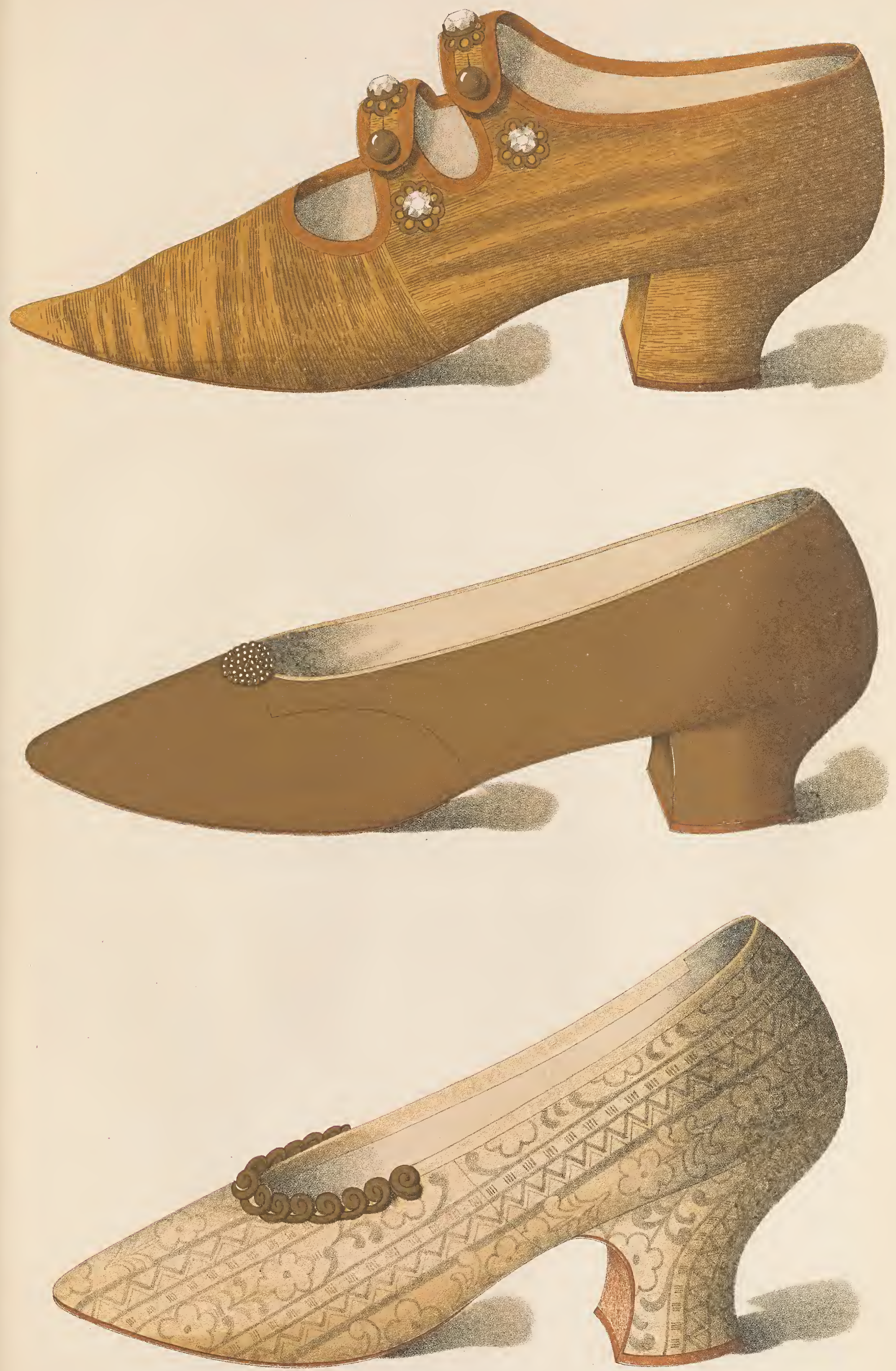



\section{Plate XVII.}

Though simply severe in style (which the richness of material demands), this shoe doubtless repeats the hue and texture of the gorgeous sweeping folds of the costume it was made to match. The paste button is neat and good, and too modest in size to publish its own failure in competition with the jewels due to the rank and toilette of the wearer. The Louis heel is also velvet-covered.

No. 2 shoe is a departure from the ordinary evening style. It must have a firmness for dancing, which is, perhaps, advantageous in some cases. The festooned embroidery in chain stitch and French knots is tastefully done in silk of darker shade, and adds to the originality of the shoe. Also a feature of it is that it is made all in one piece, and a line of stitching simulates a seam.

The last is of watered silk. The inside lining is of delicate pink satin. The buttoned strap is a favourite style with many--sometimes single, sometimes multiplied, and more or less elaborate. The plain gilt button in this case alone figures, whilst on the toe rests a small bow of watered silk ribbon exact in shade. 


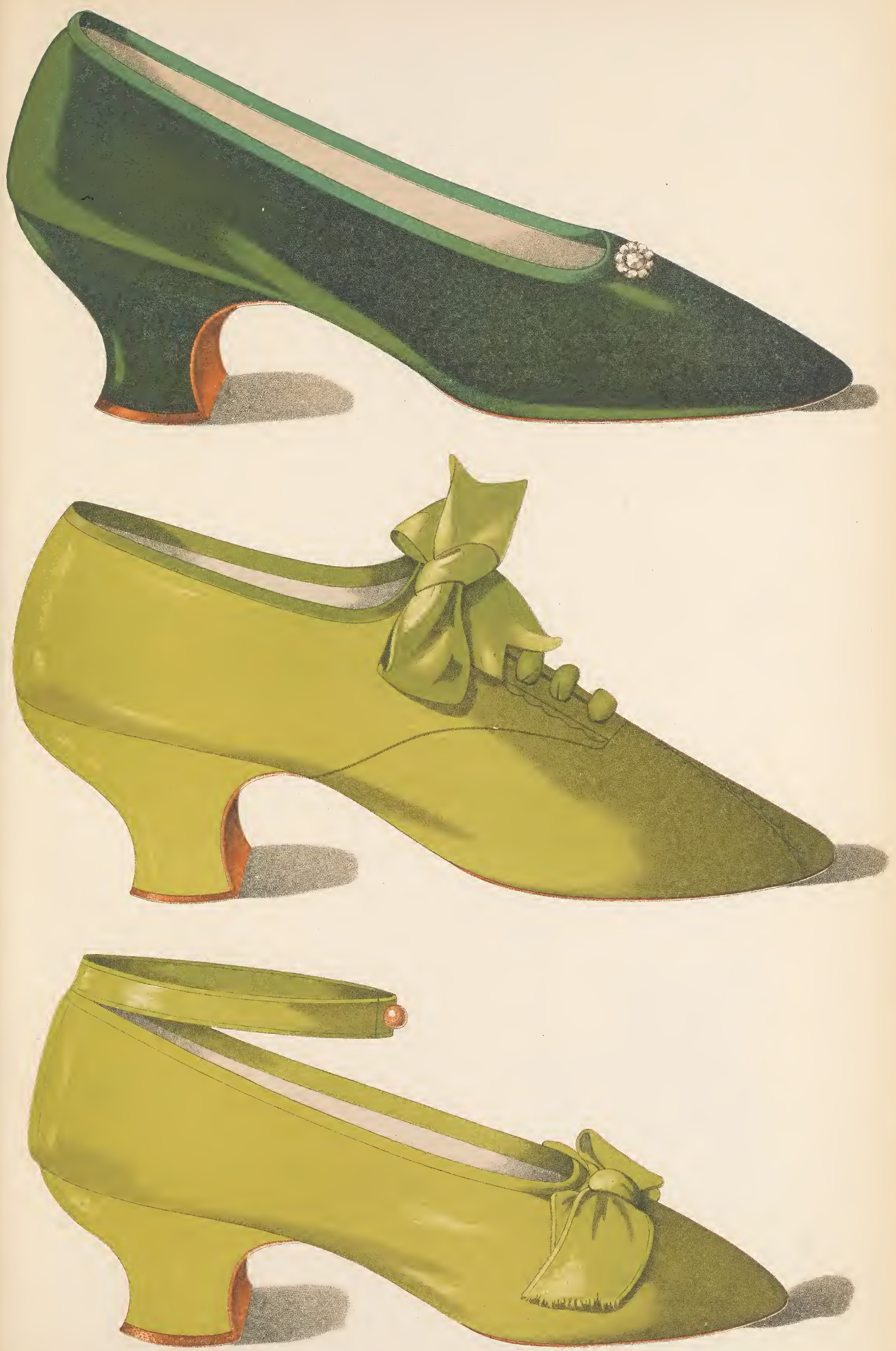



\section{Plate XVIII.}

I. Deep eau-de-nil satin shoe worn by Miss Ada Cavendish as Lady Teazle. Large rosette, with gilt and steel square buckle. This size of bow (now obsolete) admitted of an elastic insertion at the back, which, no doubt, added to the ease of fitting. The toe-cap is chain-stitched and appliqué.

The next is similar in hue, but of modern shape. It is very finely beaded, so fine as to readily conjure up the impression of a possible use of seed pearl. The toe is pointed, and the heel in Louis style.

No. 3 is also of a modern shape, the colour yellowish green. This shoe has only a Louis heel and general neatness to distinguish it. 


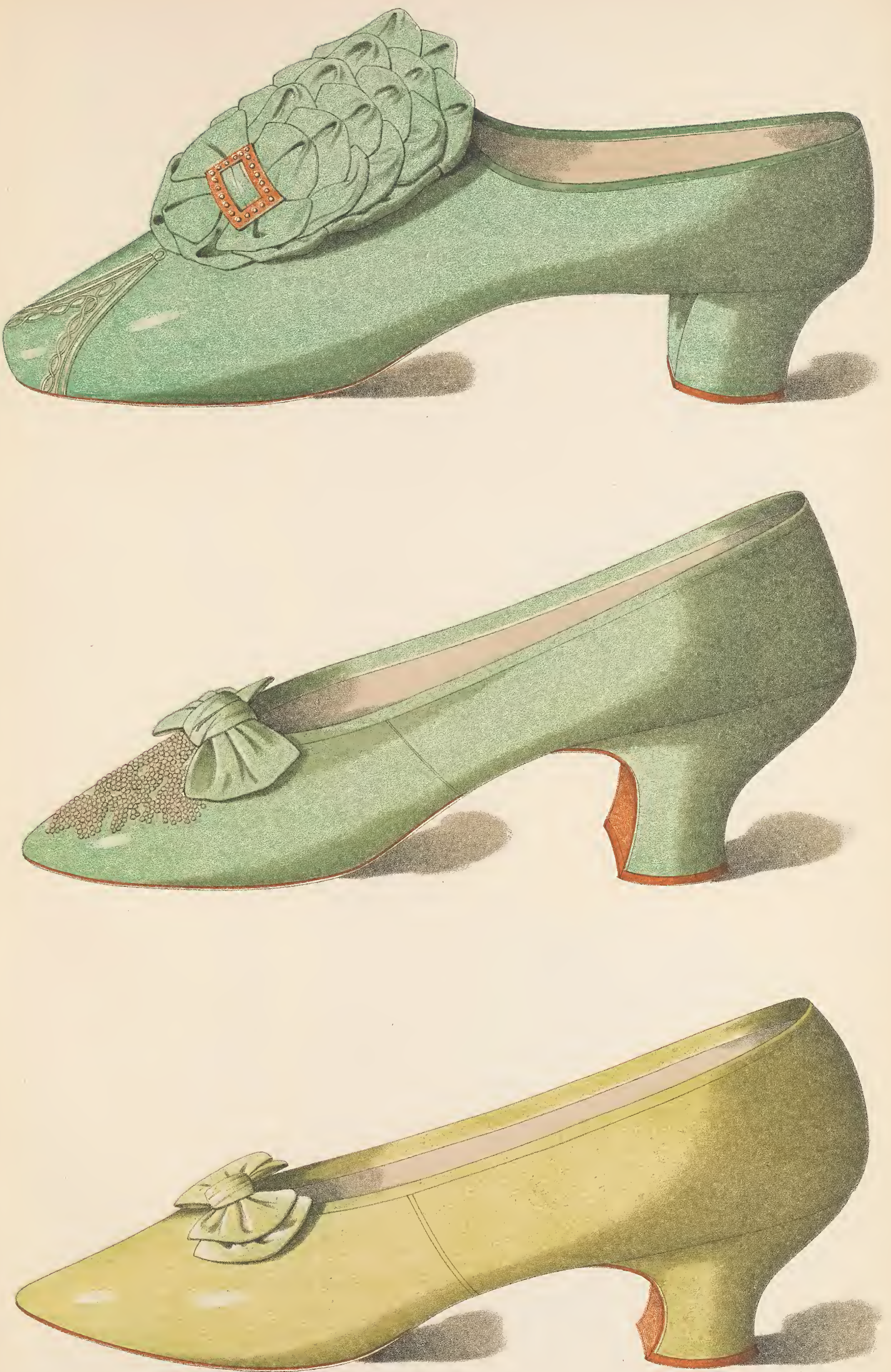



\section{Plate XIX.}

THE satin Oxford shoe again appears first on this plate. It is particularly small and neat indeed. Only the owner of a small foot could, with success, adopt this style. It is very finely embroidered in steel beads in a floral pattern. Louis heel, silk lace to match.

No. 2.-A deep red shoe, with closely embroidered toe in gold thread. It has plain silk bow to match and Louis heel.

Deep crimson also No. 3, with embroidery of rich gold thread picked out with white beads to emphasise the pattern. The rosette has rows of beads alternate red and gold, on every folded edge, and in the centre several rows. The toe is pointed; an ordinary heel. 

Plate XiX.
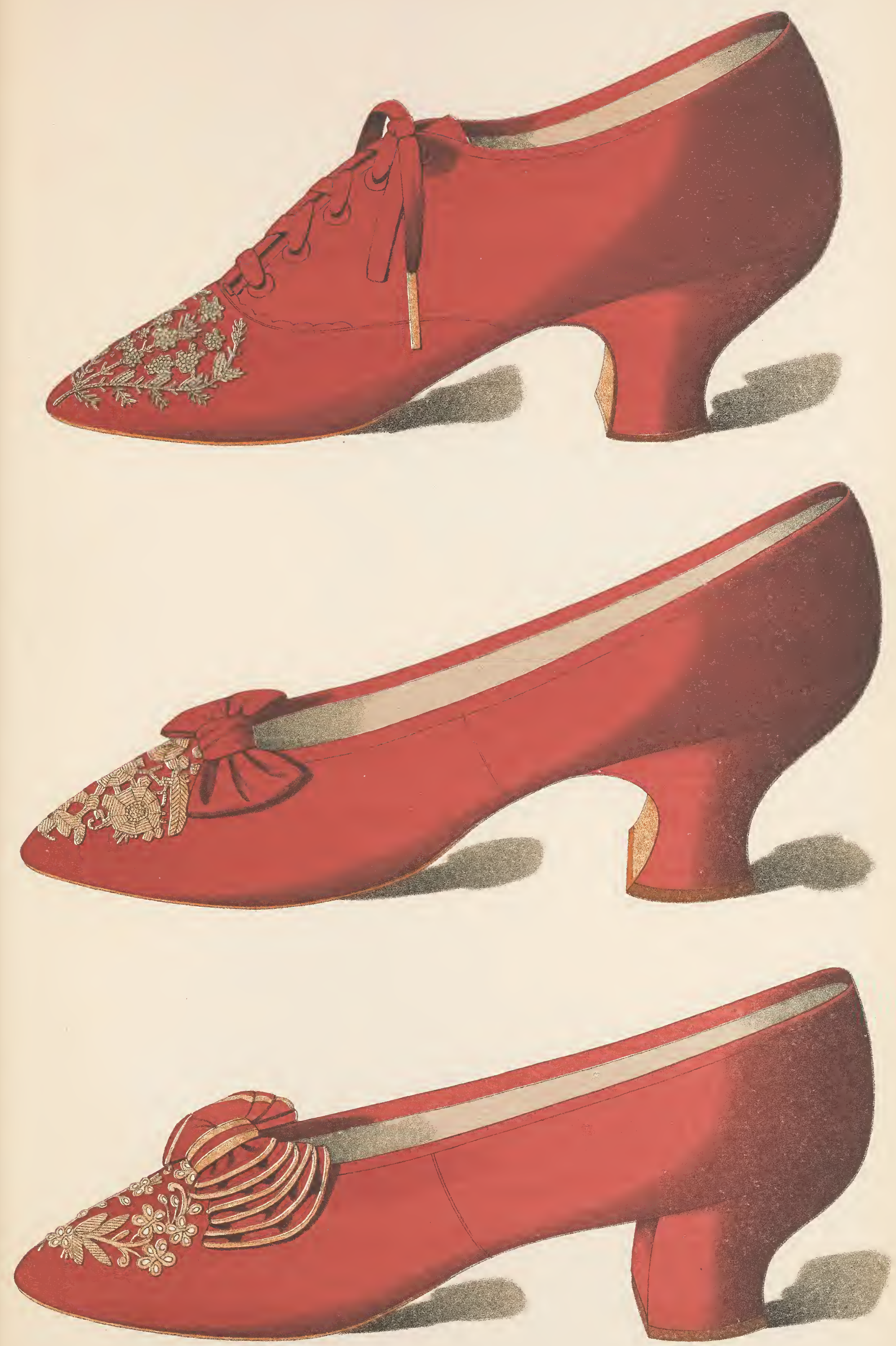



\section{Plate XX.}

THE brocade of this first shoe is rich in colour and substance. The pattern is well manipulated, so that the effect is good. The bow is of the same material.

The next shoe stands out in originality of style. The red and white satin make a vivid contrast. The piece of red attached to the vamp is sewn to the sole only, otherwise loose, and therefore would almost make necessary an ornament to fix it at the top as well and give a finish.

This shoe, the third and last, belonged to Rosa Anderson, a fair maid of Perth, whose elopement created a great sensation in bygone days in the town, to whose Council her husband belonged. Let us hope this actual pair of shoes did not carry their fair owner away to a chimerical happiness from the path of duty which appeared prosaic in the face of flattery and attention from one whose position far exceeded that of the burgher's wife. 

PlatexX.
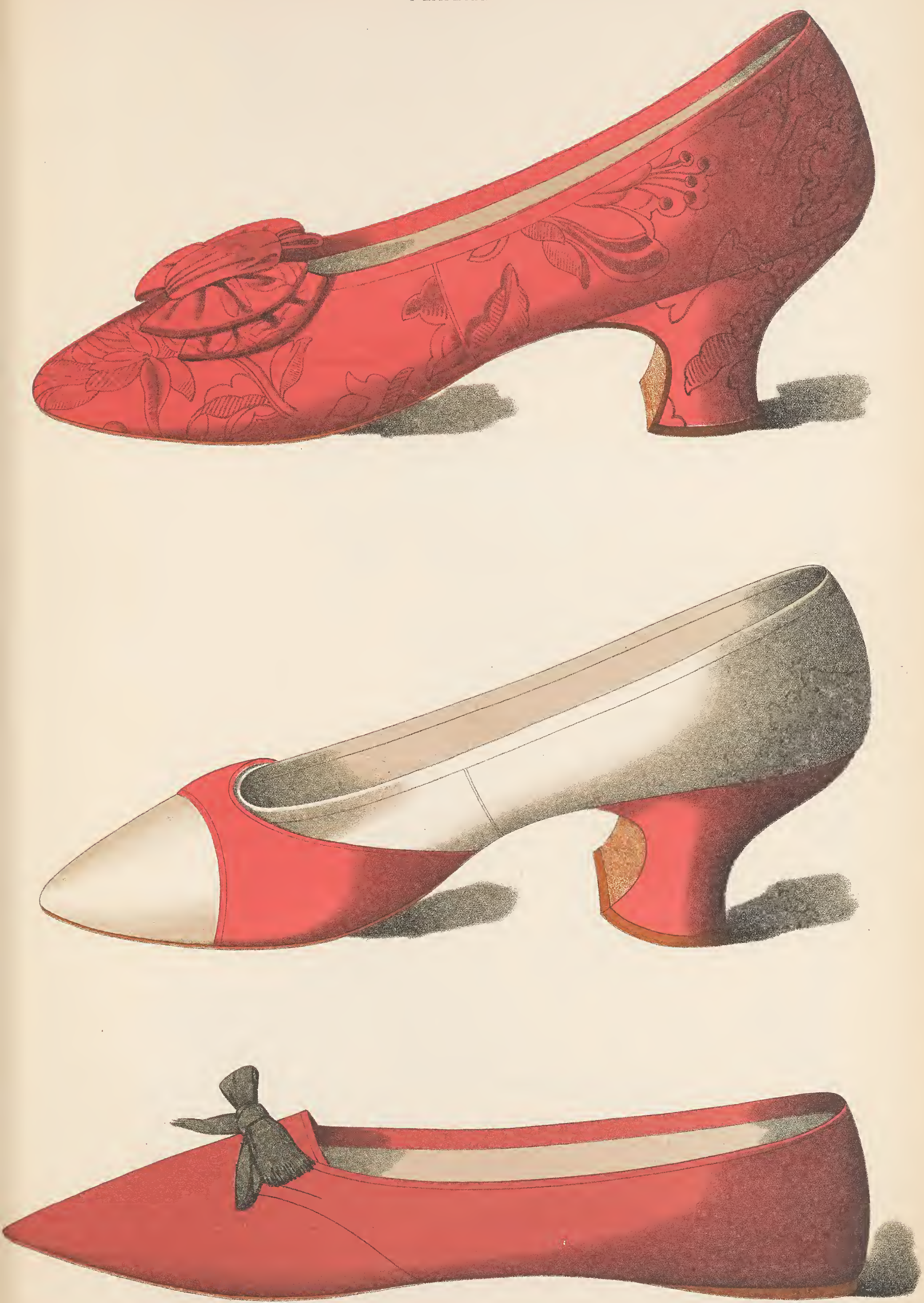



\section{Finis.}

Dancing sandals worn in the ballet by Madame Cerri, made of pink satin with pink satin ties. The soles very small, and the padded toes protruding considerably beyond them. 



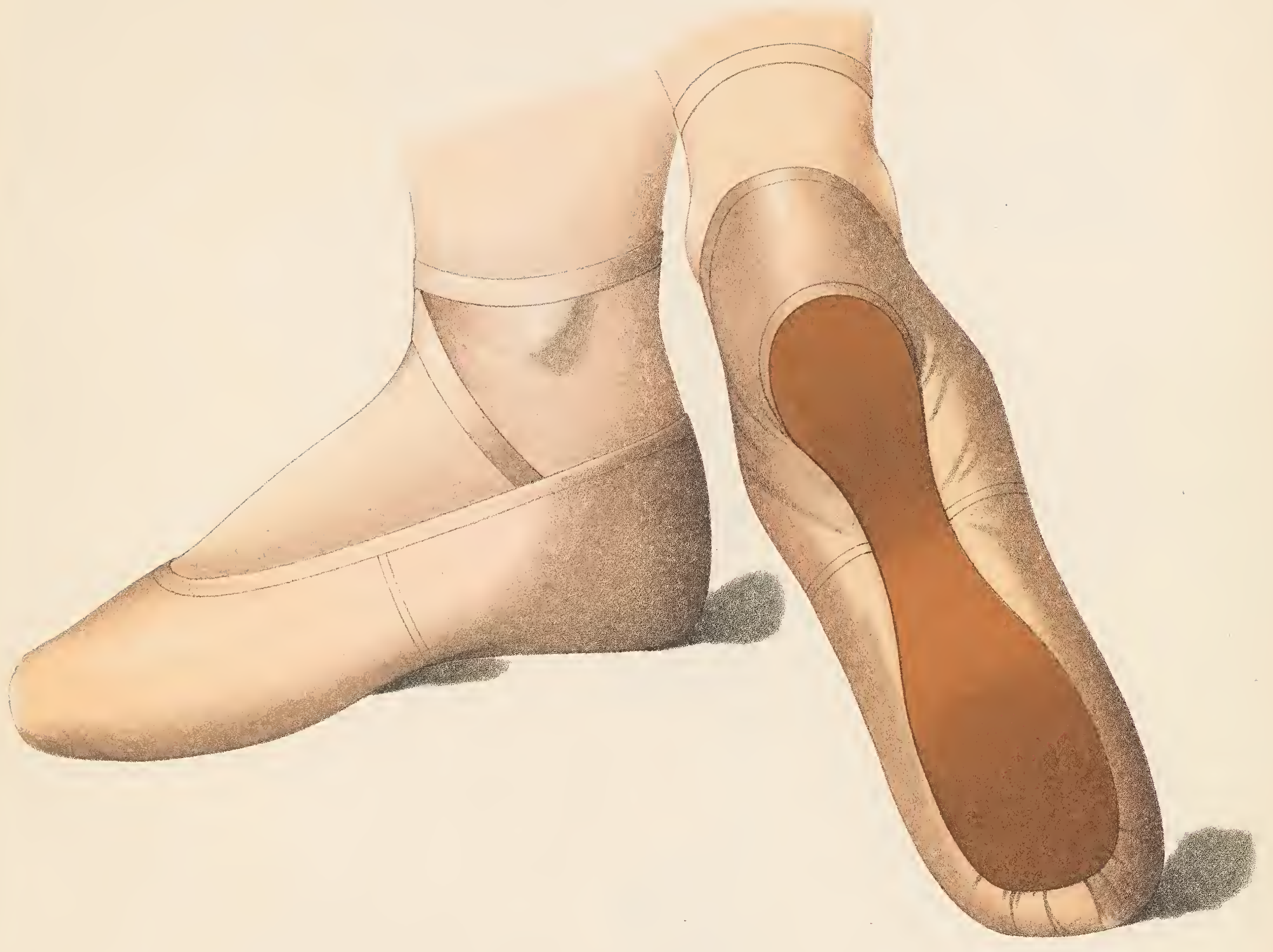





